\title{
EL MAPA HISTÓRICO DE LAS RELACIONES INTERNACIONALES
}

\section{Gerardo Rodríguez* Miguel Alegre**}

La incomprensión del presente nace fatalmente de la incomprensión del pasado. Pero no es quizás, menos vano esforzarse por comprender el pasado si no se sabe nada del presente.

Marc Bloch

El historiador quiere ser un camarógrafo capaz de captar el momento justo del cambio. Pero, como señala Marc Bloch, en su película sólo estará intacto el último cuadro y necesariamente tendrá que pasar la cinta al revés de como se tomó la escena para reconstruir los trozos de los demás cuadros. De la misma manera para un analista de las relaciones internacionales es necesario contar con un mapa de la geografía política de su momento y, a partir de éste, profundizar en las fuerzas que lo trazaron. Por lo tanto, al ser el Estado el objeto de estudio de esta disciplina es imprescindible el análisis de los cambios históricos que han dibujado y desdibujado las fronteras actuales. De esta manera, la historia se convierte en laboratorio donde los mapas perduran como la bitácora de los cambios en el tiempo y el espacio.

* Licenciatura en Relaciones Internacionales, ITAM. Director de la revista Urbi et Orbi.

** Licenciatura en Relaciones Internacionales y Diplomado en Seguridad Nacional, ITAM. 
RODRÍGUEZ Y ALEGRE

En la primera parte de este ensayo se hará un recuento de los principales acontecimientos que influyeron en el cambio de la cartografía mundial. En la segunda, a partir del conocimiento histórico de las relaciones entre los Estados, se expondrán las principales características que explican la geografía política contemporánea.

\section{Los grandes puntos de inflexión del mapa internacional}

A lo largo de la historia de las relaciones internacionales han ocurrido cambios trascendentales en la recomposición del poder político y territorial. A continuación se presentarán los hechos históricos más importantes que recompusieron el plano geográfico de la política de su momento, teniendo en cuenta que cada acontecimiento está determinado por todo un compendio de fuerzas profundas, como diría el historiador francés Pierre Renouvin. ${ }^{1}$ Para efectos de este artículo se hará énfasis en los cambios del mapa internacional y en la correlación de fuerzas entre las grandes potencias a lo largo de los últimos cinco siglos. A través de este método podremos reconstruir las imágenes de la película y, de esta manera, interpretar la última escena de las relaciones internacionales.

\section{La globalización del mundo: 1492}

1492 marca el primer punto de inflexión histórico para la conformación del sistema de internacional. En primer lugar, es el año de la ‘reconquista' de la Península ibérica y de la formación del primer Estado-nación en el mundo. En segundo lugar, es la fecha que marca el inicio de la época colonial en América e inserta a un continente por

${ }^{1}$ Según este autor en la determinación de la política exterior de los Estados influyen cuestiones económicas, comerciales, sociales, intelectuales e ideológicas. Cfr. Historia de las relaciones internacionales: siglos XIX y XX, 1998, Madrid, Akal, p. 4. 
entero a la dinámica política, económica, social e ideológica del sistema europeo. Luego de la conquista militar de América, España se convierte en la primera gran potencia del emergente sistema de Estados nacionales.

\section{La paz de Westfalia (1648)}

La Paz de Westfalia no solamente terminó con la Guerra de los Treinta años (1618-1648), sino que sentó las bases para el surgimiento de los conceptos de soberanía y Estado soberano. En el siglo que siguió a la Paz de Westfalia, la doctrina utilizada por el Cardenal Richelieu de la raison d'etat (razón de Estado) se afianzó como el principio rector de la diplomacia europea y se volvió la excusa racional de los conflictos armados en el nuevo sistema de Estados. ${ }^{2}$

Luego de la Guerra de los Treinta años y de la Paz de Westfalia emergen tres grandes potencias en el escenario internacional que van desplazando a España del liderazgo europeo: Francia, Austria y las Provincias Unidas (Holanda). Asimismo, la Paz de Westfalia dejó un vacío de poder que trataría de ser llenado por la Francia de Luis XIV.

\section{La guerra de los Siete años (1756-1763)}

La guerra de los Siete años fue un conflicto dirigido por los intereses mercantilistas británicos para destruir a Francia, su gran rival comercial, para así expandir sus mercados y consolidar sus posiciones de ultramar. Con la firma de la Paz de París (10 de febrero de 1763) que puso fin a esta conflagración, Gran Bretaña impuso su interés estratégico, con consecuencias de gran magnitud en la escena mundial.

Francia se vio obligada a ceder a la Gran Bretaña todo el territorio de Canadá, así como el comprendido entre los ríos Ohio y Mississippi. España, al ser implicada como aliada de Francia, tuvo que ceder la

${ }^{2}$ Cfr. Henry Kissinger, La diplomacia, 2000, 5a, México, FCE, p. 60. 
RODRÍGUEZ Y ALEGRE

Florida a cambio de la isla de Cuba que había sido tomada por los ingleses; pero fue compensada, bajo el principio de 'equilibrio del poder’, con la sesión francesa del territorio de la Louisiana -que más tarde regresaría a Francia y luego pasaría a Estados Unidos. La Gran Bretaña se consolida como la potencia imperial y comercial más importante del planeta al extender su dominio a las islas del Caribe y hacia Oriente en la India. ${ }^{3}$

\section{La independencia de las Américas}

El proceso de descolonización en América, que comienza con la independencia de las Trece colonias en 1776 y posteriormente de las posesiones españolas en 1810, marca un parteaguas en la conformación del sistema de Estados en el mundo. Ante el surgimiento de nuevos Estados en el continente americano, Europa deja de ser el único actor del sistema internacional. Para 1838, con la desintegración de las Provincias Unidas de Centroamérica, a lo largo del continente americano existían ya 18 Estados independientes que buscarían con mucho esfuerzos su reconocimiento en la comunidad de naciones. ${ }^{4}$

${ }^{3}$ Cfr. Jesús Velasco Márquez, "Visión panorámica de la historia de los Estados Unidos”, en Rafael Fernández de Castro y Claudia Franco Hijuelos (comp.), ¿Qué son los Estados Unidos?, 1996, México, ITAM-McGraw Hill, p. 19.

${ }^{4}$ Estados Unidos (1783), México (1821), Texas (1836-1845), Guatemala (1838), El Salvador (1838), Honduras (1838), Nicaragua (1838), Costa Rica (1838), Nueva Granada -Colombia- (1831), Venezuela (1830), Ecuador (1830), Perú (1821), Imperio del Brasil (1822), Bolivia (1825), Chile (1818), Argentina (1810), Paraguay (1811) y Uruguay (1828). La fecha entre paréntesis corresponde al año en que este Estado alcanzó su independencia. En el caso de los países centroamericanos, cuando se desintegran las Provincias Unidas de Centroamérica. 
EL MAPA HISTÓRICO

\section{El Congreso de Viena (1815)}

Luego que Europa se uniera y derrotara los intereses imperialistas de la Francia napoleónica, renació un sistema internacional que serviría de ejemplo por la estabilidad que le sucedió por casi cien años. Los artífices del Acta final del Congreso de Viena encontraron en el equilibrio físico y moral de Europa la llave de la estabilidad del mapa europeo. El equilibrio del poder redujo las oportunidades de recurrir al uso de la fuerza, mientras que el sentido de justicia compartido redujo el deseo de emplear la fuerza en las relaciones internacionales.

El equilibrio de poder en Europa se dibujó de la siguiente manera: Austria fue fortalecida con la adquisición de Lombardía y Venecia; Prusia por su parte se quedó con la Pomerania y Silesia; la República Holandesa adquirió los Países Bajos Austríacos (casi toda la actual Bélgica); Rusia recibió la parte central de Polonia y Gran Bretaña limitó sus ganancias territoriales al cabo de Buena Esperanza en África. La parte más interesante del Congreso fue que se evitó la humillación de Francia, se le invitó como potencia negociadora de la paz y sus fronteras quedaron en las originales de $1789 .^{5}$

Después de este Congreso Europa experimentó el período de paz más prolongado de su historia. Durante cuarenta años no hubo ninguna guerra entre las grandes potencias, y después de la Guerra de Crimea en 1854, no se produciría un conflicto general sino hasta la Primera guerra mundial en 1914. El lapso entre el Congreso de Viena y la Primera guerra mundial, conocido como ‘concierto europeo’, se caracterizó por una relativa paz entre las grandes potencias por dos razones fundamentales: el sistema de Congresos emanado de Viena y el respeto al equilibrio de poder en Europa. Sin embargo, en la segunda mitad del siglo XIX, el canciller alemán Otto von Bismarck empezó a gestar alianzas militares a lo largo del continente a manera de estrategia diplomática para contener cualquier amenaza al recién unificado Imperio alemán y acrecentar el poder. La salida forzada

${ }^{5}$ Cfr. Kissinger, ibid, p.74. 
RODRÍGUEZ Y ALEGRE

de Bismarck de la cancillería alemana y el derrumbe de su sistema de alianzas secretas fue un catalizador importante de la Gran guerra en 1914.

\section{El Tratado de París de 1919}

La Primera guerra mundial tiene cinco consecuencias fundamentales para la organización del sistema internacional en el siglo XX. En primer lugar, desde la guerra de Crimea, en 1854, no se había presentado una conflagración de tal magnitud que involucrara a todas las potencias europeas. En segundo lugar, es la primera vez que se gesta una guerra que involucra a Estados nacionales y colonias de cinco continentes altamente organizados, capaces de aprovechar las energías de todos sus ciudadanos o súbditos, de movilizar la capacidad productiva de las industrias pesadas y de utilizar todos los recursos de la tecnología moderna en la búsqueda de nuevos medios de destrucción. ${ }^{6}$ La tercera consecuencia de esta guerra es el agotamiento económico, político, militar y moral de Gran Bretaña, que perdería el liderazgo internacional y pasaría a los Estados Unidos. Desde ese momento quedó claro que la capital financiera del mundo en reconstrucción ya no sería Londres sino Nueva York. En cuarto lugar, el mapa político internacional sufriría una recomposición trascendental sobre todo en Europa Oriental, Medio Oriente, África y el Pacifico. El Tratado de París aplicaría selectivamente el principio de la 'autodeterminación nacional' para reconstruir las fronteras de algunos Estados en el mundo. ${ }^{7}$ Por último, esta guerra demostró que los Estados absolutistas ya no eran capaces de so-

${ }^{6}$ Cfr. David Thompson, Historia mundial de 1914 a 1968, 1997, 13a, México, FCE, p. 69.

7 "En términos generales, se dio satisfacción a las exigencias del movimiento sureño eslavo al amalgamar en Yugoslavia a Serbia, Bosnia-Herzegovina, Eslovenia y Croacia. Polonia fue reconstruida como Estado independiente; Rumania aumentó su territorio con regiones que habían pertenecido a Rusia y a Hungría; Grecia crece a costa de las posesiones turcas. Se crea una república en Checoslovaquia poblada por checos, eslavos, rutenos y alema- 
brevivir a las tensiones de este tipo de conflagraciones. Lo anterior se vio corroborado por la dimisión de Rusia a la mitad de la guerra y por el colapso de los imperios Austro-Húngaro y Otomano.

\section{La era de la posguerra y la Guerra fría}

Las dos guerras mundiales produjeron cuatro fenómenos que transformaron radicalmente el sistema internacional. Por un lado, se redujo la importancia de Europa en el mundo y emergieron como superpotencias los Estados Unidos y la Unión Soviética. Como consecuencia del vacío de poder que dejó Europa y la competencia voraz entre las dos superpotencias por el dominio del mundo irrumpió un término que influiría de manera directa en las relaciones internacionales y que marcaría toda una época: la Guerra fría. ${ }^{8}$ El mapa internacional se dividió en tres grandes bloques que trataron de mantener a su manera la estabilidad del sistema: los países ‘occidentales’, el mundo comunista y los ‘no-alineados'.

nes sudetinos. Se reconocieron como Estados independientes a las naciones bálticas de Finlandia, Estonia, Letonia y Lituania. Austria y Hungría se convirtieron en pequeños Estados separados sin salida al mar. Turquía acabó por transformarse en un nuevo y fuerte Estado bajo la dirección de Mustafa Kemal, pero limitado a Asia Menor y Constantinopla. Siria y Líbano quedaron confinados a Francia, y Palestina, Transjordania e Irak a Gran Bretaña en calidad de mandatos. Las posesiones alemanas en África fueron repartidas entre Bélgica y la Gran Bretaña. Al Japón se le dio el mandato de las islas del Pacífico septentrional; la Nueva Guinea alemana paso a Austria, y a Nueva Zelandia la Samoa alemana”, ibid., p. 95.

${ }^{8}$ La expresión fue utilizada por primera vez por el periodista Herbert Bayard Swope refiriéndose al financiero Bernard Baruch, que al comparecer en el Congreso de E.U. en 1947 dijo: "Let us not be deceived: Today we are in the midst of a cold war.” La competencia entre las dos superpotencias por el control político de algunos países comienza en 1947 cuando los Estados Unidos ofrecen ayuda económica a Grecia y a Turquía ante la presión del comunismo y la URSS. 
RODRÍGUEZ Y ALEGRE

El tercer fenómeno que surgió después de las dos guerras mundiales fue la explosión del nacionalismo en las antiguas colonias y posesiones europeas, que para 1970 conllevó al nacimiento de más de 60 nuevos países en Asia y África. Cuando se fundaron las Naciones Unidas en 1945 tenía 51 Estados-miembros, para 1968 comprendía 123, de los cuales dos terceras partes no tenían compromiso con los soviéticos o con el bloque occidental. Si bien las naciones europeas llevaron el sistema y la cultura occidental a sus posesiones de ultramar, no consiguieron consolidar regímenes estables en ellas. Por otro lado, la división artificial de las fronteras en las colonias europeas en el siglo XIX, que no respetó parámetros étnicos, fue el disparador de la mayoría de las guerras internas en estos nuevos países. Asimismo, bajo la dinámica de la Guerra fría varios conflictos nacionales fueron magnificados por las dos superpotencias en favor de sus intereses, como la Guerra de Corea (1950), Vietnam (1954-73), Cuba (1961-2), Checoslovaquia (1968), Chile (1973), Afganistán (1979) y Centroamérica durante la década de los ochenta.

Por último, la era de la posguerra se caracterizó por el nacimiento de un nuevo régimen de organizaciones internacionales. La ONU, hija del espíritu de la Sociedad de Naciones, surgió - en 1945-fundamentalmente para evitar una nueva guerra internacional en el marco de la era atómica. El ingreso a las Naciones Unidas se convirtió en la carta de aceptación para los nuevos Estados en el mundo, sin embargo, la Asamblea general y el Consejo de seguridad son el reflejo del verdadero sistema político internacional emanado de la posguerra, en donde coexisten más de una centena de países en su seno pero las decisiones en materia de seguridad internacional están reservadas únicamente a las potencias vencedoras -Estados Unidos, (URSS) Rusia, China, Francia y el Reino Unido.

El segundo régimen de organizaciones internacionales que recompuso el mapa internacional fue el que nació bajo la alineación de la Guerra fría y de los tratados de asistencia militar y económica entre los bloques de las dos superpotencias. Por el lado occidental, los Estados Unidos promovieron la creación de tres bloques de contención a la expansión del comunismo: el Tratado Interamericano de Asistencia Recíproca9 ${ }^{9}$ (TIAR) de 1947, la Organización del Tratado del Atlántico Norte ${ }^{10}$ (OTAN) de 1949, la 
Organización del Tratado de Asia Sudoriental ${ }^{11}$ (SEATO) de 1954 y la Organización del Tratado del Centro ${ }^{12}$ (CENTO) de 1959. El bloque comunista, encabezado por la Unión Soviética, promovió el Consejo para la Mutua Ayuda Económica (COMECON) entre sus países satélites como respuesta directa al Plan Marshall de los Estados Unidos para Europa Occidental. Asimismo, en 1955 se forma la Organización del Tratado de Varsovia que concertó las fuerzas armadas de Albania, Bulgaria, Checoslovaquia, Alemania Oriental, Hungría, Polonia, Rumania y la Unión Soviética.

El tercer régimen de organizaciones internacionales nació con la reunión de 44 representantes de Estado en Bretton Woods, New Hampshire, para la creación de un nuevo orden monetario internacional. El objetivo de Bretton Woods fue establecer un sistema económico capaz de prevenir un nuevo colapso económico y político -como el de la década de 1930-que desencadenara un conflicto militar. ${ }^{13}$ De aquí surgió el Fondo Monetario Internacional, para vigilar el sistema de cambios en las monedas nacionales y apoyar financieramente a los países con problemas en sus balanzas de pagos, y el Banco para la Reconstrucción y el Desarrollo (mejor conocido como el Banco Mundial), para el otorgamiento de préstamos que facilitaran la recuperación acelerada de la posguerra y promovieran el desarrollo económico internacional. El nuevo orden económico que emergió en Bretton Woods recibió dos tiros de gracia. Primero con los planes de recuperación de los Estados Unidos para Europa y después con el cambio del patrón-oro al dólar en 1971 por Richard Nixon.

${ }^{9}$ Un año después de la firma del TIAR se estableció la Organización de Estados Americanos que incorporó el Tratado de Río que da cuerpo a este pacto de seguridad entre Estados Unidos y los demás países americanos.

${ }^{10}$ Los miembros fundadores fueron Italia, Grecia, Turquía, Estados Unidos, Canadá, el Reino Unido, Francia, Dinamarca, Noruega, Islandia y Portugal.

${ }^{11}$ Sus miembros eran cinco potencias no asiáticas: Estados Unidos, el Reino Unido, Francia, Australia y Nueva Zelanda y tres Estados asiáticos: Pakistán, Filipinas y Tailandia.

${ }^{12}$ Incluía a Irán, Irak, Turquía, Pakistán, Estados Unidos y el Reino Unido.

${ }^{13}$ Joan Spero y Jeffrey Hart, The Politics of International Economic Relations, 1997, 5a, Nueva York, St. Martin’s Press, p. 8. 
RODRÍGUEZ Y ALEGRE

\section{El mapa internacional actual}

Si observamos el conjunto internacional actual, nos encontramos con la presencia de 189 Estados reconocidos por la Asamblea General de las Naciones Unidas, sin embargo de ellos solamente quince han tenido una existencia ininterrumpida por más de 200 años (España, Portugal, Francia, el Reino Unido, los Países Bajos, Suiza, Hungría, Irán, Etiopía, Omán, Nepal, China, Tailandia, Japón y Estados Unidos). ${ }^{14}$ Es decir, el mapa que hoy conocemos es el resultado de una serie de fenómenos históricos que han transformado gradualmente la extensión territorial de los Estados del orbe, como consecuencia de ganancias militares, fin de una guerra, autodeterminación, descubrimientos territoriales, anexiones imperiales o, simplemente, alianzas familiares.

El mundo durante la Guerra fría conoció la confrontación entre dos bloques ideológicos diametralmente opuestos que consiguió que cada Estado se enfrentara a la decisión de elegir el grupo al que apoyaría. Así, durante más de 40 años, la cartografía global fue el reflejo de las alianzas tejidas por las superpotencias vencedoras de la Segunda guerra mundial. Estados capitalistas, socialistas y no alineados interactuaron en un período donde un par de naciones tenían el poder de acabar con el planeta entero.

El mapa político actual es difícil de describir y analizar, dado que es reflejo de tendencias e impulsos complejos y contradictorios entrelazados. En él cada Estado se vuelve una pieza en el gran tablero de ajedrez que el capitalismo y el libre comercio controlan y en el que sólo deciden unos cuantos.

Al caer el Muro de Berlín, el 9 de noviembre de 1989, una serie de fuerzas opacadas por la confrontación ideológica pusieron de manifiesto que algo se había estado gestando durante ese período. A la par de la lucha del mundo por su propia supervivencia, dos manifestaciones

${ }^{14}$ Michael Kidron y Ronald Siegal, The State of the World Atlas, 1995, Hong Kong, Penguin References, p. 154. 
antagónicas de la modernidad se hacían cada vez más fuertes: integración y fragmentación.

Desde entonces muchos teóricos esbozan mapas futuros. Las hipótesis planteadas van desde la posible conformación del mundo por civilizaciones hasta una comunidad mundial en la que las interacciones se rigen por las áreas dominantes de la unión europea, América del Norte y la región Asia-Pacífico. Desde la década de los noventa se viene dibujando este mapa alternativo que sutituye al que tradicionalmente reconocíamos con fronteras político-nacionales, que simplifica las interestatales a relaciones económicas-comerciales. Incluso algunos analistas se aventuran a argumentar que los límites nacionales ya no responderán a las definiciones tradicionales de soberanía de los Estados sino a la conformación de bloques económicos regionales. Estas tesis adquirieron gran relevancia luego de la entrada en vigor del Tratado de libre comercio de América del Norte en 1994 y la firma del Tratado de Maastricht en 1991 que dio el gran paso para la integración de la unión europea. ${ }^{15}$ Efectivamente, un mapa de este estilo puede explicar más del 70\% del comercio internacional, sin embargo excluye por completo continentes y regiones como África, Medio Oriente, Asia central y el Sudeste asiático.

También se ha tratado de explicar el mundo actual como resultado de dos sistemas. El primero formado por los 20 o 25 Estados más desarrollados y el segundo por el resto, escenario que plantea que el primer sistema es dominante y establece la economía como eje de las relaciones.

${ }^{15}$ El objetivo del Tratado de Maastricht fue impulsar el desarrollo de la Comunidad Europea (CE) formada por doce países, para llegar a la Unión Europea (UE), que descansa sobre tres pilares: la unión económica y moneta ria (UEM), una política exterior y de seguridad común, y la cooperación en política interior y jurídica. Actualmente la Unión Europea se encuentra formada por 15 Estados: Bélgica, los Países Bajos, Luxemburgo, Italia, Alemania, Francia, Irlanda, Portugal, España, Grecia, España, Reino Unido, Austria, Suecia y Finlandia. El tratado en vigor es el de Ámsterdam, aprobado en 1997, que sustituyó al de Maastricht. 
RODRÍGUEZ Y ALEGRE

Una perspectiva que ha tenido mayor aceptación es la que divide al mundo en países del norte y del sur, sin embargo su utilidad es mínima cuando se piensa que el sur incluiría a Corea y Australia y en el norte se encontrarían Albania, Rumania y los países de la ex Unión Soviética. ${ }^{16}$

Lo mismo pasa con la teoría de 'Centro-Periferia' desarrollada bajo los estándares de la Teoría de la dependencia de los años 60. En esta teoría, centro implica a un grupo dominante de economías capitalistas; periferia a un conjunto de Estados industrial, financiera y políticamente más débiles que operan dentro de un conjunto de relaciones construidas por los miembros del centro. Bajo esta visión cabrían también un grupo de Estados que se encontrarían en una etapa de desarrollo más avanzada que la de los países de la periferia y menor a la de los países del centro, que conformaría la 'semi-periferia’ y aspiraría a formar parte del centro.

Las perspectivas antes mencionadas pasan por alto que las fuerzas que dan forma a la cartografía mundial son diversas y centrífugas. En el mundo actual no hay una sola teoría que explique la totalidad del sistema internacional, y por lo tanto se necesita de varias explicaciones.

Fuerzas opuestas han ido dándole un nuevo rostro a las tradicionales definiciones de Estado y soberanía, ahora gracias al intercambio comercial y a los avances tecnológicos es posible que dos personas estén más cerca, aun cuando una esté en Nueva York y la otra en Bangkok. Pero también es posible que dos vecinos estén muy lejos religiosa y culturalmente hablando; que la distancia de una calle sea el equivalente a la distancia real entre las ciudades antes mencionadas y ambos pugnen por crear una nueva nación, excluyente y homogénea.

Integración versus fragmentación, ser parte o no; esta lucha se manifiesta al interior de muchos Estados, en grandes regiones del mundo y en continentes enteros. Europa sería el ejemplo más claro de la intensa lucha en la que se enfrentan integración y fragmentación. La Unión

${ }^{16}$ Cfr. Barry Buzan, "New Patterns of Global Security in the Twenty First Century” en Steven Spiegel y David Pervin, At Issue Politics in the World Arena, 1994, Nueva York, St. Martin’s Press, p. 238. 
Europea es la primera gran fuerza de la que son parte la gran mayoría de los estados soberanos de Europa occidental. Sin embargo, hay Estados europeos, que se niegan a ser integrados -como Suiza-mientras que otros pugnan por ser parte de ésta -como la República Checa, Eslovaquia, Polonia, Rumania, Bulgaria, Hungría, Eslovenia, Chipre, Malta y las Repúblicas Bálticas.

Por otro lado, la misma Europa ha sido escenario de una de las fragmentaciones más cruentas y dolorosas de la historia de la posguerra fría (Croacia, Eslovenia, Bosnia-Herzegovina, Krajina, Kosovo). La desintegración de Estados que se creían consolidados durante el lapso que duró la Guerra fría evidenció que las diferencias ideológicas no sólo eran políticas sino también religiosas y culturales. Paralelamente encontramos fenómenos de desintegración nacional en Indonesia (Timor Oriental, Iran Jaya y las Molucas) así como en la región del Cáucaso: Chechenia y Daguestán.

El sueño del fin de la Historia, ${ }^{17}$ según el cual la confrontación ideológica habría sido el último estadio que daría paso a un mundo unificado bajo los estándares del liberalismo demostró ser una precipitación histórica. De la misma manera la teoría de Huntington del choque de las civilizaciones ${ }^{18}$ mostró que el mundo era un lugar mucho más complejo que el de pocos años antes.

La terrorífica certidumbre que la confrontación entre Estados Unidos y la ex Unión Soviética proporcionaba se convirtió en una gran incertidumbre al caer la 'cortina de hierro'. El mundo es ahora la 'aldea global', ha dejado la bipolaridad atrás y fortalece las instituciones democráticas en muchas regiones, ${ }^{19}$ pero no por esto el planeta es un lugar más seguro.

Guerras étnicas en diversos continentes, fundamentalismos religiosos exacerbados, pugnas territoriales y deseos de autodeterminación nos hacen darnos cuenta de que la única constante de la realidad internacional, y

${ }^{17}$ Cfr. Francis Fukuyama, El fin de la historia y el último hombre, 1993, Nueva York, Avon Books.

${ }^{18}$ Samuel P. Huntington, The Clash of Civilizations: The Remaking of the World Order, 1997, Nueva York, Simon and Shuster. 
RODRÍGUEZ Y ALEGRE

por ende reflejo geopolítico, es el cambio, que no sólo genera incertidumbre sino una fuente persistente de tensión que pone en riesgo la frágil seguridad internacional.

El concepto de destrucción mutua asegurada ${ }^{20}$ proporcionaba tranquilidad al sistema internacional, ya que sólo bajo una circunstancia excepcional alguna de las potencias se vería forzada a comenzar un ataque nuclear, con lo que se aseguraba la estabilidad que necesitaba el mundo para garantizar la paz. En la actualidad el constante cambio podría ser el detonante de nuevas amenazas a la estabilidad que perdió su garantía en 1989.

Las fragmentaciones que viven naciones enteras en África no hacen pensar en riesgo de inestabilidad, pero si observamos fenómenos semejantes en Macedonia, Montenegro y Serbia podemos darnos cuenta de que el incremento en la tensión de los conflictos podría motivar una nueva guerra y en consecuencia cambios territoriales. Bajo esa situación, no sólo Europa se vería en serias dificultades que pondrían en tela de juicio su propia estabilidad y la de sus instituciones, sino que podría generar un conflicto de mayores dimensiones entre países o regiones que hoy comparten un mismo sistema económico, pero también las tensiones heredadas de la Guerra fría y las ambiciones de las grandes potencias.

Asimismo, los procesos bajo el estandarte de la integración económica tampoco son garantía de estabilidad ni el signo del fin de la historia, aunque la probabilidad de conflictos por motivos comerciales es muy baja. Las tensiones entre bloques comerciales, sea cual sea su etapa de integración, son permanentes y parecen aumentar, tales son los casos de Estados Unidos y la Unión Europea o de Japón y Estados Unidos,

${ }^{19}$ Los países de América Latina serían el ejemplo más palpable de este hecho, ya que han experimentado un creciente apoyo de la sociedad civil a la democracia y sus instituciones.

${ }^{20}$ Consistente en el cambio de una táctica ofensiva por una de disuasión apoyada en la capacidad que ambos estados tenían para aniquilarse mutuamente, que permitió que tanto Estados Unidos como la Unión Soviética evitaran una confrontación nuclear. 
pero también dentro de los mismos bloques ya 'integrados' hay conflictos, y las disputas comerciales entre México y Estados Unidos son muestra de ello.

El continuo proceso de integración genera inestabilidad dentro de los Estados, ya que sectores en su interior se oponen a la creciente pérdida de soberanía, a los costos que esto conlleva y a la posible evaporación de las fronteras nacionales. El impacto del libre comercio causa estragos en sectores desfavorecidos y fomentará el crecimiento de organizaciones que lo resistan.

Integración y fragmentación son fuerzas de cambio que en parte explican el mapa contemporáneo, también las teorías Norte-Sur y Centro-Periferia, sin embargo no son suficientes para analizar todas las fuerzas y fenómenos que interactúan en la conformación del panorama político actual.

Bajo las fuerzas de integración y fragmentación el mundo sigue y seguirá transformándose y por ende su configuración geopolítica. La mayoría de los actuales Estados-nación son resultado del proceso evolutivo descrito en la primera parte de este ensayo, sin embargo la constante del mapa político actual es la complejidad de las fuerzas políticas, económicas, sociales y culturales que dibujan un mundo heterogéneo. 
